\title{
Tubular approach to minimally invasive microdiscectomy for pediatric lumbar disc herniation
}

\author{
Julio D. Montejo, BA, ${ }^{1}$ Joaquin Q. Camara-Quintana, MD, ${ }^{1}$ Daniel Duran, MD, ${ }^{1}$ \\ Jeannine M. Rockefeller, MSN, APRN, ${ }^{1}$ Sierra B. Conine, ${ }^{1}$ Alyssa M. Blaise, ${ }^{1}$ \\ Kristopher T. Kahle, MD, PhD, ${ }^{1-3}$ and Michael L. DiLuna, MD ${ }^{1,2}$ \\ Departments of ${ }^{1}$ Neurosurgery, ${ }^{2}$ Pediatrics, and ${ }^{3}$ Cellular \& Molecular Physiology and Centers for Mendelian Genomics, Yale \\ School of Medicine, New Haven, Connecticut
}

\begin{abstract}
OBJECTIVE Lumbar disc herniation (LDH) in the pediatric population is rare and exhibits unique characteristics compared with adult LDH. There are limited data regarding the safety and efficacy of minimally invasive surgery (MIS) using tubular retractors in pediatric patients with LDH. Here, the outcomes of MIS tubular microdiscectomy for the treatment of pediatric LDH are evaluated.
\end{abstract}

METHODS Twelve consecutive pediatric patients with LDH were treated with MIS tubular microdiscectomy at the authors' institution between July 2011 and October 2015. Data were gathered from retrospective chart review and from mail or electronic questionnaires. The Macnab criteria and the Oswestry Disability Index (ODI) were used for outcome measurements.

RESULTS The mean age at surgery was $17 \pm 1.6$ years (range $13-19$ years). Seven patients were female (58\%). Prior to surgical intervention, $100 \%$ of patients underwent conservative treatment, and $50 \%$ had epidural steroid injections. Preoperative low-back and leg pain, positive straight leg raise, and myotomal leg weakness were noted in 100\%, 83\%, and $67 \%$ of patients, respectively. The median duration of symptoms prior to surgery was 9 months (range 1-36 months). The LDH level was L5-S1 in $75 \%$ of patients and L4-5 in $25 \%$. The mean \pm SD operative time was $90 \pm 21$ minutes, the estimated blood loss was $\leq 25 \mathrm{ml}$ in $92 \%$ of patients (maximum $50 \mathrm{ml}$ ), and no intraoperative or postoperative complications were noted at 30 days. The median hospital length of stay was 1 day (range $0-3$ days). The median follow-up duration was 2.2 years (range $0-5.8$ years). One patient experienced reherniation at 18 months after the initial operation and required a second same-level MIS tubular microdiscectomy to achieve resolution of symptoms. Of the 11 patients seen for follow-up, 10 patients (91\%) reported excellent or good satisfaction according to the Macnab criteria at the last follow-up. Only 1 patient reported a fair level of satisfaction by using the same criteria. Seven patients completed an ODI evaluation at the last follow-up. For these 7 patients, the mean ODI low-back pain score was 19.7\% (SEM 2.8\%).

CONCLUSIONS To the authors' knowledge, this is the longest outcomes study and the largest series of pediatric patients with LDH who were treated with MIS microdiscectomy using tubular retractors. These data suggest that MIS tubular microdiscectomy is safe and efficacious for pediatric LDH. Larger prospective cohort studies with longer follow-up are needed to better evaluate the long-term efficacy of MIS tubular microdiscectomy versus other open and MIS techniques for the treatment of pediatric LDH.

https://thejns.org/doi/abs/10.3171/2017.11.PEDS17293

KEY WORDS adolescents; lumbar disc herniation; minimally invasive surgery; microdiscectomy; spine

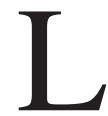

UMBAR disc herniation (LDH) is a well-known cause of low-back pain and lower-extremity radiculopathy in adults. ${ }^{13}$ However, LDH is rare in the pediatric population, with children accounting for only $5 \%$ of LDH cases. ${ }^{15}$ While the pediatric pathophysiology is not fully understood, certain risk factors, including trauma, developmental anatomical variants, and genetics, may predispose certain patients to symptomatic LDH..$^{6,14,15}$ Moreover, unlike the degenerative discs frequently seen in adults, herniated pediatric discs tend to be highly elastic and

ABBREVIATIONS BMI = body mass index; EBL = estimated blood loss; LDH = lumbar disc herniation; LOS = length of stay; MIS = minimally invasive surgery; ODI = Oswestry Disability Index. 
nondegenerative in nature, thereby predisposing pediatric patients to poorer resorption and poorer response to conservative management. ${ }^{8,15}$

The approach to adult and pediatric LDH has historically included open laminectomy with discectomy, which is an approach that dates back to the mid-20th century. ${ }^{17}$ More recently, minimally invasive surgery (MIS) techniques have grown in favor because of their ability to preserve important muscle attachments and avoid excessive bone removal, which may compromise spinal stability. ${ }^{5}$ These concepts are especially important in children and adolescents because they undergo significant growth with a continuously changing skeletal structure. MIS approaches for pediatric $\mathrm{LDH}$ presently include keyhole laminotomy with the use of a microscope to perform microdiscectomy ${ }^{16}$ and percutaneous endoscopic microdiscectomy. ${ }^{9,12,18,19}$ Short-term follow-up studies of microdiscectomy for pediatric LDH have shown comparable results to those of traditional open discectomy, thus validating MIS techniques in pediatric patients..$^{16}$ However, few studies have looked at the safety and efficacy of using a tubular approach for MIS microdiscectomy as a treatment option for pediatric $\mathrm{LDH}{ }^{16}$

The purpose of this study was 2-fold: 1) to characterize the unique clinical features seen in pediatric patients with LDH who require surgery, and 2) to evaluate and validate the perioperative, postoperative, short-term, and longerterm outcomes of MIS tubular microdiscectomy for the treatment of pediatric LDH.

\section{Methods \\ Patients}

The inclusion criteria for this case series were 1) pediatric patients who were 19 years or younger; 2) diagnosis of LDH based on physical findings and MRI examination; 3) surgical treatment with MIS tubular microdiscectomy; and 4) date of surgery between July 2011 and October 2015. There were 12 consecutive pediatric patients who underwent surgical treatment performed by the senior author (M.L.D.) and met all inclusion criteria. None of these 12 patients had a history of spinal oncology, prior spinal infection, acute fracture to the spine due to trauma, known isthmic spondylolisthesis, or lumbar instability on imaging. Every operation took place in a pediatric operating room. Patients admitted to the hospital following surgery stayed on a pediatric ward. The institutional review board at Yale University School of Medicine approved the study.

\section{Preoperative Evaluation}

The electronic medical records were reviewed independently by 3 authors (J.D.M., S.B.C., and J.Q.C.-D.) to determine all chart review data as documented by the treating neurosurgeon. Demographic variables included age at surgery and sex. Risk factors included body mass index (BMI), participation in athletic activities, precipitating trauma, comorbidities, and tobacco use. Presurgical treatment variables included the use of nonsteroidal antiinflammatory drugs, opioid pain medication, physical therapy, chiropractor therapy, epidural steroid injection, as well as the number of emergency department visits due to low-

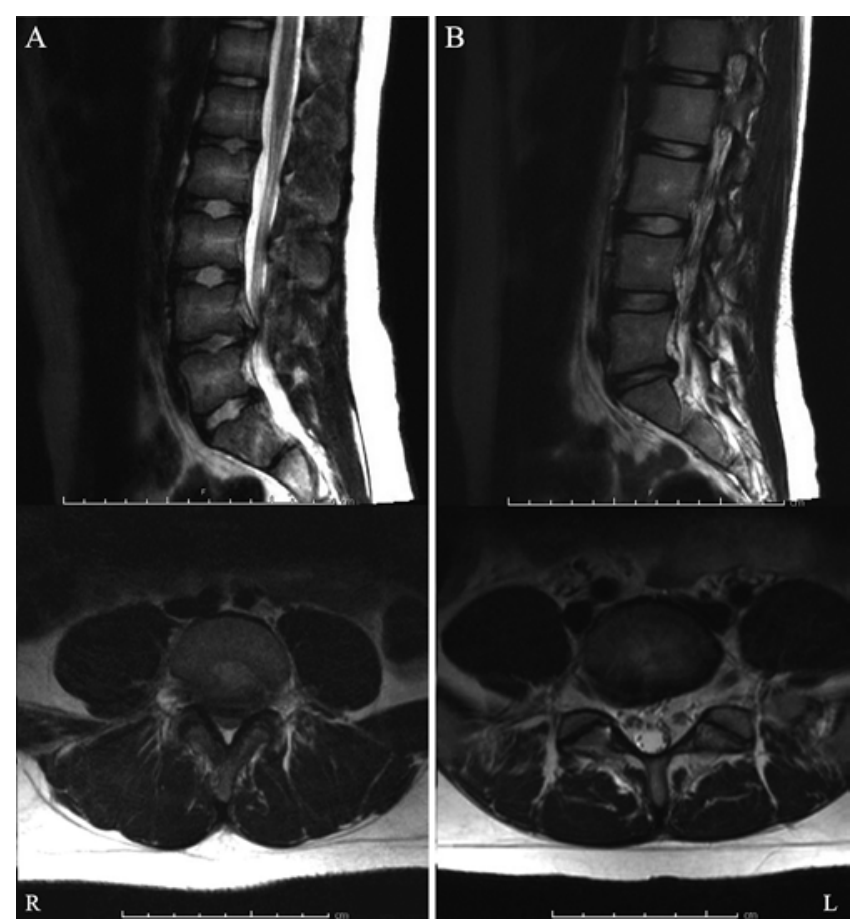

FIG. 1. Representative radiological images of pediatric LDH. A: Preoperative sagittal (upper) and axial (lower) T2-weighted magnetic resonance images of a pediatric case of LDH at L4-5. B: LDH at L5-S1. Note the significant narrowing of the spinal canal that is highlighted by the reduction of the cerebrospinal fluid signal at the level of herniation.

back pain and radicular pain prior to surgical intervention. Variables at presentation included duration of symptoms prior to surgery, presence of radicular low-back pain or leg pain, and bladder or bowel dysfunction. Variables at physical examination included positive straight leg raise, myotomal lower-extremity weakness, and dermatomal sensory loss. All patients underwent diagnostic preoperative MRI evaluation of the lumbar spine, as well CT or plain radiography when indicated. MRI findings were reviewed as documented by the treating neurosurgeon and radiologist. Fig. 1 illustrates the representative LDH findings on MRI of typical cases included in this cohort. Every patient had at least 4 months of conservative therapy before being considered for surgery unless the presence of neurological deficits, as exemplified by myotomal lower-extremity weakness, justified more urgent surgical intervention.

\section{Surgical Technique}

Written informed consent was obtained from all patients or their guardians. All patients were placed under general anesthesia during surgery. No patient required a Foley catheter. Patients were placed prone on a Jackson table with a Wilson frame. A $<15$-mm paramedian incision about $1 \mathrm{~cm}$ off the midline was made, and a tubular retractor system (most commonly METRx [Medtronic], but MARS3 V [Globus Medical] and Luxor [Stryker] were also used depending on availability) was docked against the medial facet and inferior lateral edge of the lamina at the level and side of the herniated disc. The position and angle of the tubular retractor system was confirmed with 
the use of intraoperative fluoroscopy. When the final 14or $18-\mathrm{mm}$-diameter tubular retractor was in place, an operative microscope was brought in, hemilaminotomy and medial facetectomy were performed, and the underlying ligamentum flavum was removed to expose the underlying impinged nerve root (Fig. 2). The herniated disc was identified, its annulus incised, and its nucleus pulposus resected. The wound was irrigated, and the fascial, deep dermal, and subcuticular layers were closed using absorbable sutures. No dural tears or changes in monitoring data were noted in any of the surgeries.

\section{Outcomes Evaluation}

The electronic medical records were reviewed to determine perioperative and postoperative outcomes. Perioperative variables included operative time, estimated blood loss (EBL), and any complications. Patients typically underwent clinical follow-up at 2 weeks to 1 month, 3 months, 6 months, and 1 year postoperatively and as needed thereafter. Postoperative variables included hospital length of stay (LOS) and reason for hospital admission. Follow-up outcome variables included follow-up duration, 30-day complications, need for revision surgery, and symptomatology at the last follow-up. Additionally, the Macnab criteria ${ }^{10}$ were used to assess patient satisfaction at the last follow-up. Postoperative complications were defined as any adverse outcome that occurred within the first 30 days following surgery; adverse outcomes included new neurological deficits or the need for revision surgery. Additional follow-up was obtained by a mailed or electronic self-reported questionnaire. The validated Oswestry Disability Index (ODI) ${ }^{4}$ questionnaire was used to evaluate the functional status of our patients at the last follow-up.

\section{Statistical Analysis}

Mean, SD, SEM, and range values were calculated for the normally distributed continuous variables (age at surgery, BMI, and operative time) and are reported as the mean \pm SD (range) or mean (SEM). Median and range values were calculated for nonnormally distributed continuous variables (duration of symptoms, LOS, and follow-up duration) and are reported as the median (range). Group percentages were calculated for the categorical variables where the denominator for each percentage is equal to the number of available or applicable data. Based on the observed results, EBL was dichotomized as $\leq 25 \mathrm{ml}$ versus $\geq 25 \mathrm{ml}$, and the reason for the hospital stay was dichotomized as parent preference versus pain control. Other variables were dichotomized as present versus absent.

\section{Results}

Patient-specific features and outcomes are summarized in Table 1.

\section{Preoperative Features}

The mean patient age at surgery was $17 \pm 1.6$ years (range 13-19 years), there were 7 female patients (58\%), the female/male ratio was 1.4 , and the mean BMI was $23.8 \pm$
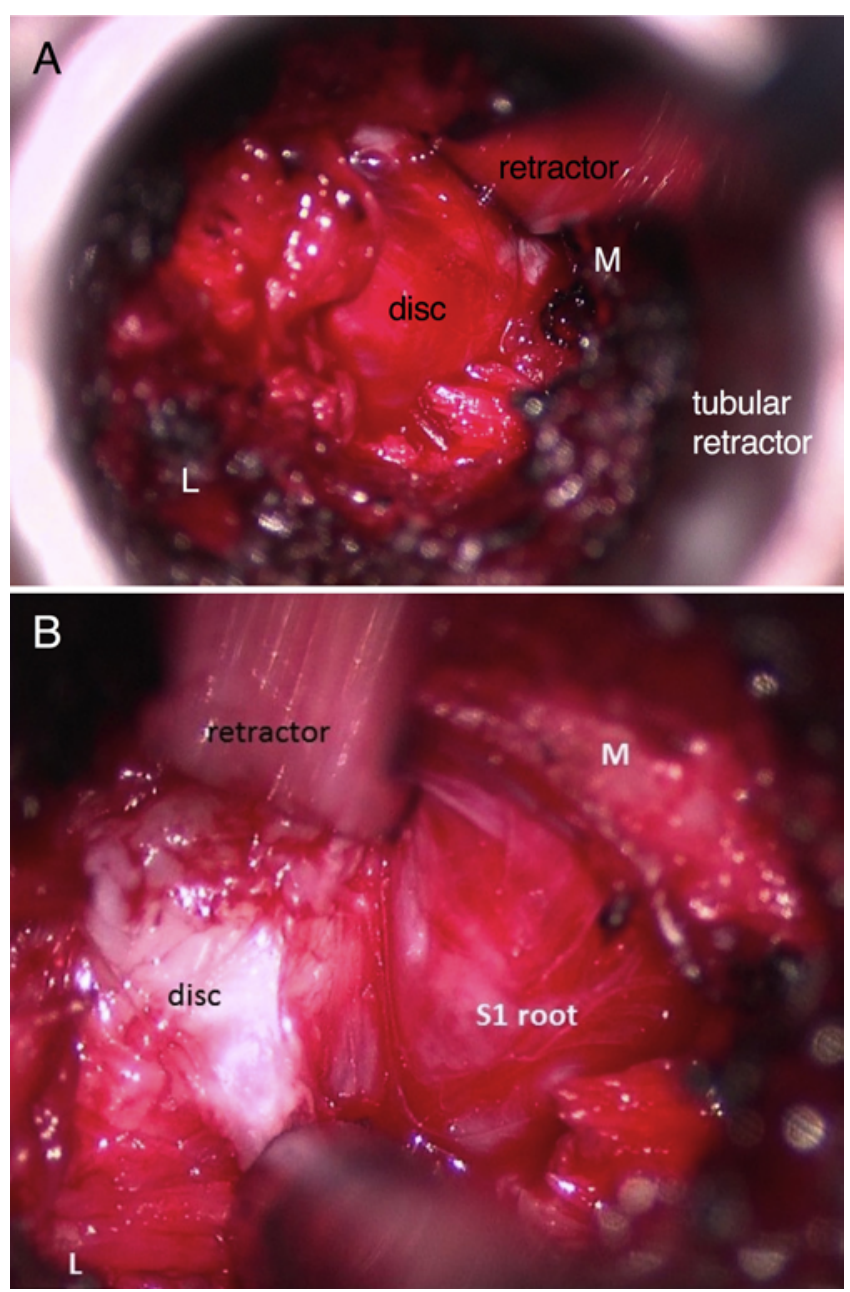

FIG. 2. Representative surgical view through the operating microscope during MIS microdiscectomy using tubular retractors to treat pediatric LDH. A: Lower magnification view peripherally demonstrating the tubular retractors. B: Higher magnification view. $L=$ lateral; $M=$ medial.

$6 \mathrm{~kg} / \mathrm{m}^{2}$ (range $16.3-35.1 \mathrm{~kg} / \mathrm{m}^{2}$ ). A history of competitive athletic activities, precipitating trauma, and comorbidities was present in 67\% (8 of 12), 33\% (4 of 12), and 58\% (7 of 12) of patients, respectively. Predisposing comorbidities or anatomical variants included singular cases of 1) contralateral index-level Bertolotti's syndrome (lumbosacral transitional L-5 vertebra) with an associated L5-S1 alar pseudojoint; 2) history of Chiari type I malformation (postdecompression status) with an index-level lumbosacral transitional S-1 vertebra and an S1-2 false disc; 3) Tarlov cyst; and 4) levoconvex thoracic scoliosis with a syrinx. None of our patients had a history of tobacco use.

Prior to surgical intervention, $100 \%$ (12 of 12) of patients underwent conservative treatment modalities $(100 \%$ of patients received nonsteroidal antiinflammatory drugs, $42 \%$ received opioid medication, $75 \%$ received physical therapy, and $8.3 \%$ received chiropractor therapy), but only $50 \%$ (6 of 12) of patients had an epidural steroid injection and $50 \%$ visited the emergency department due to low-back and radicular leg pain. The median duration of radicular symptoms prior to surgery was 9 months (range 
TABLE 1. Summary of 12 consecutive patients with pediatric LDH treated with MIS tubular microdiscectomy

\begin{tabular}{|c|c|c|c|c|c|c|c|c|c|c|}
\hline $\begin{array}{l}\text { Age } \\
\text { (yrs), } \\
\text { Sex }\end{array}$ & $\begin{array}{l}\text { Pain } \\
\text { Duration } \\
\text { (mos) }\end{array}$ & $\begin{array}{l}\text { Myotomal } \\
\text { Leg } \\
\text { Weakness* }\end{array}$ & Level & $\begin{array}{c}\text { Intraop } \\
\text { EBL } \\
(\mathrm{ml}) \dagger\end{array}$ & $\begin{array}{c}\text { LOS } \\
\text { (days), } \\
\text { Reason }\end{array}$ & $\begin{array}{c}\text { Follow-Up } \\
\text { (yrs) }\end{array}$ & $\begin{array}{c}\text { 30-Day } \\
\text { Complications }\end{array}$ & Pain \& Weakness Outcome & $\begin{array}{l}\text { Macnab } \\
\text { Criteria }\end{array}$ & $\begin{array}{l}\text { Low-Back } \\
\text { Pain ODI } \\
\text { Category }\end{array}$ \\
\hline $17, \mathrm{~F}$ & 9 & $4 \mathrm{DF}$ & L5-S1 & Minimal & 1, PP & 5.8 & No & Weakness resolved \& pain improved & Good & Moderate \\
\hline $18, M$ & 2 & $4 \mathrm{DF}, 3 \mathrm{EHL}$ & L5-S1 & Minimal & 0 & 0 & NA & Lost to follow-up & NA & NA \\
\hline $16, F$ & 12 & None & L5-S1 & Minimal & 1, PP & 2.0 & No & Pain resolved (required redo op) & Excellent & NA \\
\hline $19, \mathrm{~F}$ & 6 & $4 \mathrm{TA}$ & L4-5 & Minimal & 1, PP & 3.3 & No & Weakness \& pain resolved & Excellent & Minimal \\
\hline $18, M$ & 11 & $\begin{array}{l}4 \text { DF/PF \& } \\
4 \text { EHL }\end{array}$ & L5-S1 & Minimal & 1, PP & 3.0 & No & Weakness resolved \& persistent pain & Fair & Severe \\
\hline $17, \mathrm{M}$ & 12 & $4 \mathrm{TA} / \mathrm{EHL}$ & L5-S1 & Minimal & 0 & 2.8 & No & Weakness \& pain resolved & Excellent & Minimal \\
\hline $15, \mathrm{~F}$ & 36 & $4 \mathrm{TA} / \mathrm{EHL}$ & L4-5 & Minimal & $3, P C$ & 0.5 & No & Weakness resolved \& pain improved & Good & NA \\
\hline $18, \mathrm{~F}$ & 4 & None & L5-S1 & Minimal & 0 & 0.1 & No & Pain resolved & Excellent & NA \\
\hline $13, M$ & 1 & $4 \mathrm{TA} \& 3 \mathrm{EHL}$ & L4-5 & Minimal & 1, PP & 2.6 & No & Weakness \& pain resolved & Excellent & Minimal \\
\hline $16, F$ & 6 & None & L5-S1 & Minimal & 1, PP & 2.1 & No & Weakness \& pain resolved & Excellent & Minimal \\
\hline $18, \mathrm{~F}$ & 18 & None & L5-S1 & Minimal & 2, PC & 2.2 & No & Pain improved & Good & Moderate \\
\hline $17, \mathrm{M}$ & 9 & 4 DF \& 3 EHL & L5-S1 & 50 & 1, PP & 0.2 & No & Weakness resolved \& pain improved & Good & NA \\
\hline
\end{tabular}

$\mathrm{DF}=$ dorsiflexion; $\mathrm{EHL}=$ extensor hallucis longus; $\mathrm{NA}=$ not available; $\mathrm{PC}=$ pain control; $\mathrm{PF}=$ plantar flexion; $\mathrm{PP}=$ parent preference; $\mathrm{TA}=$ tibialis anterior.

* Muscle group strength was measured on an ascending scale from 0 (completely flaccid) to 5 (normal strength).

$\dagger$ Minimal EBL was defined as $\leq 25 \mathrm{ml}$.

1-36 months). Preoperative signs and symptoms of radicular low-back and leg pain, positive straight leg raise, and myotomal leg weakness were notable in $100 \%$ (12 of 12), $83 \%$ (10 of 12), and $67 \%$ (8 of 12) of patients, respectively. However, dermatomal sensory loss was notable in only $17 \%$ (2 of 12) of patients, and none experienced bladder or bowel dysfunction. The level of LDH was L5-S1 in 75\% (9 of 12) and L4-5 in 25\% (3 of 12) of patients, respectively, and $58 \%$ (7 of 12) of patients had LDH on the left side.

\section{Perioperative and Postoperative Outcomes}

The mean operative time was $90 \pm 21$ minutes (range 46-124 minutes), and EBL was $\leq 25 \mathrm{ml}$ in $92 \%$ (11 of 12) of patients (maximum $50 \mathrm{ml}$ in 1 patient). There were no intraoperative or postoperative complications at 30 days. Postoperatively, the median LOS was 1 day (range 0-3 days), with $25 \%$ (3 of 12) of patients discharged on the day of surgery. The primary reason for a 1-night hospital admission was parent preference to ensure continued adequate pain control and voiding status. The primary reason for more than 1 night of admission was inadequate pain control, with 1 patient additionally developing a urinary tract infection in the absence of an indwelling catheter for which appropriate antibiotics were started while the patient was still in the hospital.

\section{Longer-Term Outcomes}

The overall median follow-up time for our cohort was 2.2 years (range $0-5.8$ years). Eleven of 12 patients $(92 \%)$ underwent follow-up. Of those 11 patients, 1 patient (9.1\%) experienced a recurrence of radicular symptoms at 18 months after the initial operation and required a second same-level MIS tubular microdiscectomy, which successfully resolved the patient's symptoms. At the last followup, symptoms had completely resolved or significantly improved in $91 \%$ (10 of 11) of our patients, while 1 (9.1\%) patient did not significantly improve. Correspondingly, the Macnab criteria at the last follow-up revealed that 91\% (10 of 11) of patients had excellent or good patient satisfaction, while 1 patient $(9.1 \%)$ had fair satisfaction.

Seven of 11 patients (64\%) completed an ODI questionnaire at a median follow-up of 2.8 years (range 2.1-5.8 years). According to the ODI results, $57 \%$ of our patients (4 of 7) had minimal features of low-back pain, while 2 patients (29\%) had mildly moderate features and another patient (14\%) had mildly severe features due to adjacentlevel degenerative disease. Detailed ODI section analysis revealed that our cohort had minimal features of low-back pain in 7 sections (personal care, social life, walking, sleeping, sex life, traveling, and pain intensity) and moderate features in 3 sections (standing, sitting, and lifting). On average, our cohort demonstrated a low-back pain score on ODI of $19.7 \%$ (SEM 2.8\%). The ODI results are summarized in Fig. 3 and detailed in Table 2.

\section{Discussion}

Few studies have investigated outcomes after MIS tubular microdiscectomy for pediatric LDH. Despite being introduced by Foley and Smith in 1997 for adults, ${ }^{5}$ the first reported case series on the short-term outcomes of MIS tubular microdiscectomy for pediatric LDH was not performed until 14 years later in 2011 by Thomas et al., ${ }^{16}$ which included only 6 patients. To the best of our knowledge, there have been no further reports, thereby making our study the longest outcomes study and the largest.

Pediatric LDH is rare, and although this patient population tends to respond less to conservative management,, 15 many patients do respond and are never seen by a spine specialist. ${ }^{2}$ Thus, it is generally agreed that in the absence of neurological deficits or intractable pain, conservative 
A

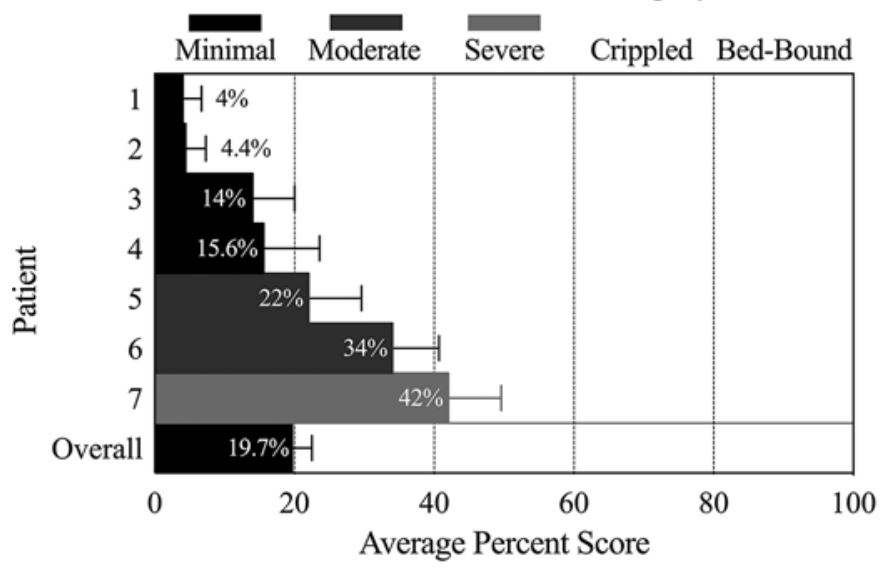

C

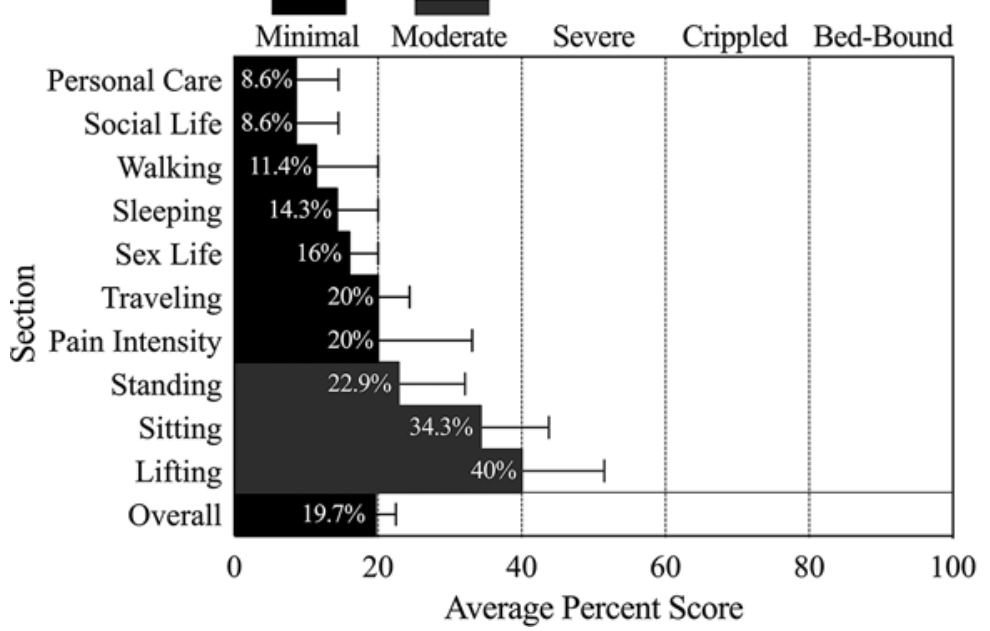

B Percent of Patients

ODI Low-Back

Pain Category

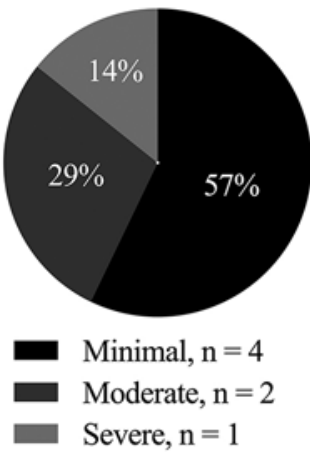

D Percent of Sections

ODI Low-Back Pain Category

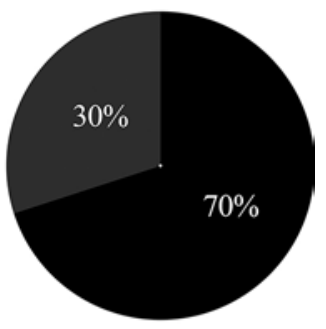

Minimal, $\mathrm{n}=7$

Moderate, $\mathrm{n}=3$

FIG. 3. Outcomes of MIS tubular microdiscectomy for pediatric LDH. ODI results for 7 of 12 patients with pediatric LDH (4 female patients) who were treated with MIS tubular microdiscectomy at a median follow-up of 2.8 years (range 2.1-5.8 years). A: Low-back pain category on ODI per patient and overall. B: Percentages of patients in each low-back pain category on ODI. C: Low-back pain category on ODI per section and overall. D: Percentages of sections in each low-back pain category on ODI. Error bars represent SEM.

therapy should be attempted prior to the consideration of surgical options. In our study, all patients were managed conservatively for at least 4 months unless the degree of weakness prompted more urgent surgical intervention.

Our study recapitulated some of the typical presenting features of pediatric LDH that have been reported in the literature. Given that pediatric LDH occurs much less frequently in children younger than 12 years, it comes as no surprise that all of our patients were adolescents. ${ }^{15}$ Many of our patients participated in competitive athletic activities,${ }^{15}$ several presented after precipitating trauma, ${ }^{6}$ and several had predisposing comorbidities or anatomical variants, including lumbosacral transitional vertebrae, ${ }^{1}$ scoliosis, ${ }^{11}$ Tarlov cyst, and Chiari type I malformation. Moreover, only 1 level was involved in each case at either L5-S1 (75\%) or L4-5 (25\%). Lastly, all of our patients presented with low-back pain and lower-extremity radicular symptoms (most had a positive straight leg raise sign), and none experienced bladder or bowel dysfunction. ${ }^{15}$
Interestingly, although the literature does not reveal a clear sex predominance in pediatric LDH, the female/ male ratio has been previously reported to be increased in certain cohorts. ${ }^{15}$ The female/male ratio in our surgical series was greater at 1.4, thereby providing further evidence that female adolescents may be more likely to present with symptoms of LDH and undergo surgery. Moreover, unlike previous reports where motor symptoms were noted in $40 \%-50 \%$ of patients with pediatric $\mathrm{LDH},{ }^{2}$ our study noted such findings in $67 \%$ of patients. However, our cohort may have been biased by greater disease severity given our threshold for surgical intervention.

This case series provides further evidence of the safety and efficacy of MIS tubular microdiscectomy for the treatment of $\mathrm{LDH}$ in the pediatric population. Intraoperative EBL was minor ( $\leq 25 \mathrm{ml}$ in $92 \%$ of cases; maximum $50 \mathrm{ml}$ ), there were no intraoperative or 30-day postoperative complications, and most patients returned home on either the day of surgery or the 1st postoperative day. The 
TABLE 2. ODI results for 7 of 12 patients with pediatric LDH treated with MIS tubular microdiscectomy

\begin{tabular}{|c|c|c|c|c|c|c|c|c|c|c|c|c|}
\hline Variable & & & & Value & & & & $\begin{array}{l}\text { Sum } \\
\text { Total }\end{array}$ & $\begin{array}{l}\text { Sum } \\
\text { Max }\end{array}$ & Percentage & SEM & $\begin{array}{l}\text { Low-Back Pain } \\
\text { ODI Category* }\end{array}$ \\
\hline \multicolumn{13}{|l|}{ Patient characteristics } \\
\hline Age at surgery, yrs & 17 & 19 & 18 & 17 & 13 & 16 & 18 & & & & & \\
\hline Sex & $\mathrm{F}$ & $\mathrm{F}$ & M & M & M & $\mathrm{F}$ & $\mathrm{F}$ & & & & & \\
\hline Follow-up, yrs & 5.8 & 3.3 & 3 & 2.8 & 2.6 & 2.1 & 2.2 & & & & & \\
\hline \multicolumn{13}{|l|}{ ODI section† } \\
\hline Pain intensity & 4 & 0 & 3 & 0 & 0 & 0 & 0 & 7 & 35 & 20 & 13.1 & Min \\
\hline Personal care & 2 & 0 & 1 & 0 & 0 & 0 & 0 & 3 & 35 & 8.6 & 5.9 & Min \\
\hline Lifting & 2 & 2 & 3 & 0 & 3 & 0 & 4 & 14 & 35 & 40 & 11.5 & Mod \\
\hline Walking & 0 & 0 & 3 & 0 & 0 & 0 & 1 & 4 & 35 & 11.4 & 8.6 & Min \\
\hline Sitting & 2 & 2 & 4 & 0 & 2 & 1 & 1 & 12 & 35 & 34.3 & 9.5 & Mod \\
\hline Standing & 2 & 0 & 3 & 1 & 0 & 0 & 2 & 8 & 35 & 22.9 & 9.2 & Mod \\
\hline Sleeping & 1 & 2 & 1 & 0 & 0 & 0 & 1 & 5 & 35 & 14.3 & 5.7 & Min \\
\hline Sex life & 1 & 0 & 1 & 1 & NA & NA & 1 & 4 & 25 & 16 & 4 & Min \\
\hline Social life & 2 & 0 & 1 & 0 & 0 & 0 & 0 & 3 & 35 & 8.6 & 5.9 & Min \\
\hline Traveling & 1 & 1 & 1 & 0 & 2 & 1 & 1 & 7 & 35 & 20 & 4.4 & Min \\
\hline \multicolumn{13}{|l|}{ ODI score } \\
\hline Total sum & 17 & 7 & 21 & 2 & 7 & 2 & 11 & 67 & & & & \\
\hline Max sum & 50 & 50 & 50 & 50 & 45 & 45 & 50 & & 340 & & & \\
\hline Percentage & 34 & 14 & 42 & 4 & 15.6 & 4.4 & 22 & & & 19.7 & & \\
\hline SEM & 6.7 & 6 & 7.6 & 2.7 & 8 & 2.9 & 7.6 & & & & 2.8 & \\
\hline Low-back pain ODI category* & Mod & Min & Sev & Min & Min & Min & Mod & & & & & Min \\
\hline
\end{tabular}

Max = maximum; $\min =$ minimum; mod $=$ moderate $;$ sev $=$ severe.

* Per ODI definitions: minimal $=0 \%-20 \%$; moderate $=21 \%-40 \%$; severe $=41 \%-60 \%$; crippled $=61 \%-80 \%$; and bed-bound $=81 \%-100 \%$.

$\dagger$ Self-scored from 0 (best quality of life) to 5 (worst quality of life).

majority of patients who remained in the hospital overnight postoperatively did so due to parent preference to ensure continued adequate pain control and voiding status. Prior studies of other MIS techniques have reported shortterm complications that could similarly be encountered in patients treated using the tubular approach. These complications include wound hematoma and delayed wound healing, which are reported in up to $4 \%$ and $3 \%$ of cases, respectively, as well as rare surgical wound infections or discitis. ${ }^{15}$ However, our patients did not experience any short-term complications.

We monitored the majority of our cohort (92\%) for median 2.2 years and maximum 5.8 years postoperatively. Per the Macnab criteria, $91 \%$ of patients had excellent or good patient satisfaction at the last follow-up. Furthermore, on average, our cohort demonstrated a low-back pain score on ODI of $19.7 \%$ (SEM 2.8\%) at the last follow-up, thereby indicating borderline minimal or moderate low-back pain interference in overall quality of life. Our findings further substantiate the aforementioned improvements in reduced low-back pain and radicular leg pain and weakness after using MIS tubular microdiscectomy to treat pediatric LDH.

Long-term complications reported by studies of other MIS techniques include disc space narrowing, foraminal stenosis, adjacent-disc degeneration, and a variable risk of reherniation that requires reoperation (range 0\%-24\%).,7
In our cohort, 1 patient $(9.1 \%)$ experienced lumbar disc reherniation at 18 months after the initial operation and required reoperation with an MIS tubular approach. Furthermore, while most patients had minimal or only mildly moderate features of low-back pain on ODI, the ODI responses of 1 patient were $2 \%$ over the threshold for severe features and necessitated further improvement in all elements of pediatric LDH, including conservative management, preoperative evaluation, and postoperative management.

Our study has several limitations. The significant limitations are the retrospective nature of this study and the cohort size, which predispose the study to selection and sampling bias. To address potential bias, we included consecutive patients in our study. Importantly, our study represents the results of a single neurosurgeon at a single institution. Given the rarity of pediatric LDH in patients who are younger than 13 years, our study consisted of pediatric teenagers (13 years or older), and thus we cannot make conclusions about the safety or efficacy of the tubular approach for MIS microdiscectomy in patients who are younger than 13 years. Lastly, the preoperative ODI scores or those at the intermediate follow-up intervals were not available for comparison against the ODI scores at the last follow-up, thereby precluding a more complete assessment of the postsurgical trend in improvement relative to presurgical baseline. 
Further observational studies, and ideally randomized clinical trials involving larger pediatric LDH cohorts with longer follow-up durations, are needed to validate and expand our findings and to investigate relative efficacy across different types of MIS techniques. Additional long-term outcomes after MIS tubular microdiscectomy that are in need of investigation include the incidence of iatrogenic pars defects, adjacent-segment changes, and the need for lumbar spine fusion.

\section{Conclusions}

To our knowledge, this is the longest outcomes study and the largest series of pediatric patients with LDH who were treated with MIS microdiscectomy using tubular retractors. Our data suggest that MIS tubular microdiscectomy is safe and efficacious for pediatric LDH. Larger prospective cohort studies with longer follow-up durations are needed to better evaluate the long-term efficacy of MIS tubular microdiscectomy versus other open and MIS techniques for the treatment of pediatric LDH.

\section{Acknowledgments}

We thank our patients and their families for the opportunity to participate in their care.

\section{References}

1. Ahn SS, Chin DK, Kim SH, Kim DW, Lee BH, Ku MG: The clinical significance of lumbosacral transitional vertebrae on the surgical outcomes of lumbar discectomy: a retrospective cohort study of young adults. World Neurosurg 99:745-750, 2017

2. Cahill KS, Dunn I, Gunnarsson T, Proctor MR: Lumbar microdiscectomy in pediatric patients: a large single-institution series. J Neurosurg Spine 12:165-170, 2010

3. Durham SR, Sun PP, Sutton LN: Surgically treated lumbar disc disease in the pediatric population: an outcome study. $\mathbf{J}$ Neurosurg 92 (1 Suppl):1-6, 2000

4. Fairbank JC, Pynsent PB: The Oswestry Disability Index. Spine (Phila Pa 1976) 25:2940-2952, 2000

5. Foley KT, Smith MM: Microendoscopic discectomy. Tech Neurosurg 3:301-307, 1997

6. Haidar R, Ghanem I, Saad S, Uthman I: Lumbar disc herniation in young children. Acta Paediatr 99:19-23, 2010

7. Ishihara $\mathrm{H}$, Matsui $\mathrm{H}$, Hirano N, Tsuji H: Lumbar intervertebral disc herniation in children less than 16 years of age. Long-term follow-up study of surgically managed cases. Spine (Phila Pa 1976) 22:2044-2049, 1997

8. Lavelle WF, Bianco A, Mason R, Betz RR, Albanese SA: Pediatric disk herniation. J Am Acad Orthop Surg 19:649_ 656, 2011

9. Lee DY, Ahn Y, Lee SH: Percutaneous endoscopic lumbar discectomy for adolescent lumbar disc herniation: surgical outcomes in 46 consecutive patients. Mt Sinai J Med 73:864-870, 2006

10. Macnab I: Negative disc exploration. An analysis of the causes of nerve-root involvement in sixty-eight patients. J Bone Joint Surg Am 53:891-903, 1971

11. Matsui H, Ohmori K, Kanamori M, Ishihara H, Tsuji H: Significance of sciatic scoliotic list in operated patients with lumbar disc herniation. Spine (Phila Pa 1976) 23:338-342, 1998

12. Mayer HM, Mellerowicz H, Dihlmann SW: Endoscopic discectomy in pediatric and juvenile lumbar disc herniations. $\mathbf{J}$ Pediatr Orthop B 5:39-43, 1996

13. Mixter WJ, Barr JS: Rupture of the intervertebral disc with involvement of the spinal canal. N Engl J Med 211:210-215, 1934

14. Patel AA, Spiker WR, Daubs M, Brodke D, Cannon-Albright LA: Evidence for an inherited predisposition to lumbar disc disease. J Bone Joint Surg Am 93:225-229, 2011

15. Slotkin JR, Mislow JMK, Day AL, Proctor MR: Pediatric disk disease. Neurosurg Clin N Am 18:659-667, 2007

16. Thomas JG, Hwang SW, Whitehead WE, Curry DJ, Luerssen TG, Jea A: Minimally invasive lumbar microdiscectomy in pediatric patients: a series of 6 patients. J Neurosurg Pediatr 7:616-619, 2011

17. Wahren H: Herniated nucleus pulposus in a child of twelve years. Acta Orthop Scand 16:40-42, 1945

18. Wang X, Zeng J, Nie H, Chen G, Li Z, Jiang H, et al: Percutaneous endoscopic interlaminar discectomy for pediatric lumbar disc herniation. Childs Nerv Syst 30:897-902, 2014

19. Zheng C, Wu F, Cai L: Transforaminal percutaneous endoscopic discectomy in the treatment of far-lateral lumbar disc herniations in children. Int Orthop 40:1099-1102, 2016

\section{Disclosures}

The authors report no conflict of interest concerning the materials or methods used in this study or the findings specified in this paper.

\section{Author Contributions}

Conception and design: DiLuna, Kahle. Acquisition of data: Montejo, Camara-Quintana, Conine. Analysis and interpretation of data: DiLuna, Montejo, Camara-Quintana, Duran. Drafting the article: Montejo, Camara-Quintana. Critically revising the article: DiLuna, Montejo, Camara-Quintana, Duran, Rockefeller, Blaise, Kahle. Reviewed submitted version of manuscript: all authors. Approved the final version of the manuscript on behalf of all authors: DiLuna. Statistical analysis: Montejo, Camara-Quintana. Administrative/technical/material support: Montejo, Rockefeller. Study supervision: DiLuna, Kahle.

\section{Supplemental Information}

\section{Previous Presentations}

Excerpts from this work were presented at the New England Neurosurgical Society Annual Meeting in Chatham, Massachusetts, on June 22-24, 2017.

\section{Correspondence}

Michael L. DiLuna: Yale School of Medicine, New Haven, CT. michael.diluna@yale.edu. 